Психология. Журнал Высшей школы экономики.

2010. T. 7, № 3. С. 57-71.

\title{
ВЛИЯНИЕ ИНТЕРНЕТ-АКТИВНОСТИ НА МНЕМИЧЕСКИЕ СПОСОБНОСТИ СУБЪЕКТА
}

\author{
Л.В. ЧЕРЕМОШКИНА
}

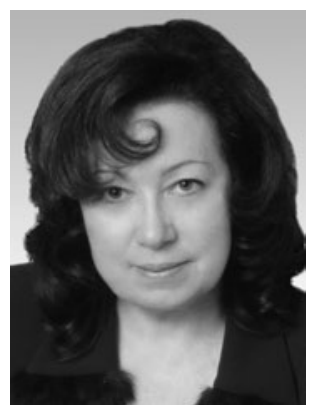

Черемошкина Любовь Валерьевна - профессор Московского городского психолого-педагогического университета, доктор психологических наук, профессор. Сфера научных интересов - психология памяти, психология способностей, проблема депрофессионализации, психология Интернета.

Автор книг «Мнемические способности: диагностика и развитие» (2009, в соавт.), «Психология памяти» $(2002,2009)$.

Контакты: LVCH2007@yandex.ru

В статье показана специфика влияния длительного и систематического использования Интернет-ресурсов на мнемические способности субъекта. Представлены результаты исследования запоминания простого, усложненного и наиболее сложного невербального бессмысленного материала пользователями Интернет-ресурсов 11 и 16 лет, 18-20 лет, 25-35 лет со стажем Интернет-активности до одного года, до полутора лет, от полутора до трех лет, свыше трех, свыше шести и свыше десяти лет.

Ключевые слова: мнемические способности, функииональные механизмы, операционные механизмы, регулирующие механизмы, влияние

Интернет-активности.

В свое время Ж. Пиаже отметил, что развитие психической деятельности является функцией от все увеличивающихся масштабов взаимодействия человека с окружающим миром (Пиаже, 1966). Принципиально новую среду функционирования и развития психических процессов создали Интернет-ресурсы, обеспечивающие почти безграничные мас- штабы информационного взаимодействия. Интернет, с одной стороны, расширяет возможности получения новых знаний. С другой, характер «добывания» (получения) нового знания иной, информация структурирована, «подготовлена» для использования. Человек, познающий мир через Интернет, превращается в человека, потребляющего кем-то

Работа выполнена при финансовой по поддержке РГНФ, проект № 08-06-00378а. 
воспринятую, обработанную и оформленную информацию. Чем раньше происходит процесс вовлечения в процессы использования Сети, тем в большей степени человек приучается поглощать заготовленные оценки, суждения и умозаключения. Тем самым активный субъект Интернет-ресурсов может превращаться в объект влияния, манипулирования или управления с помощью соответствующим образом оформленного содержания. Человек «заглатывает» переработанную («неживую») информацию, не требующую от него самостоятельного анализа и индивидуальной оценки.

Каким образом в условиях виртуальной реальности функционирует познавательная сфера человека? Как сформированные в условиях киберактивности познавательные процессы проявляются в реальном мире?

Изучение познавательных способностей людей, систематически использующих различные виды информационных технологий, позволит прогнозировать закономерности жизни человека в условиях информационного общества в связи с появлением новых возможностей удовлетворения потребностей и с учетом тех способностей, которые обеспечивают пребывание и достижение целей в киберпространстве.

Способности как инструментальные характеристики познавательной активности являются стереотипизированными психическими процессами, закрепившимися филогенетически и развивающимися онтогенетически в виде психических свойств. Стереотипизация психического процесса обусловлена, с одной стороны, характером взаимодействия человека с окружающим миром, а с другой особенностями мозговых структур, включающими как структурно-морфологические свойства мозга, так и показатели его рефлекторной деятельности. Все возрастающие возможности использования Интернет-ресурсов замещают необходимость взаимодействия с реальным миром. Совершенно очевидно, что длительное пребывание в киберсреде создает условия для закрепления новых (иных) алгоритмов поведения, иначе говоря, приводит к стереотипизации новых (иных) психических деятельностей. Это означает, что систематическое использование информационных технологий, в частности Интернет-ресурсов, может приводить к появлению новых или специфически трансформированных способностей.

Ранее нами (Черемошкина, 2008; Черемошкина и др., 2009) были получены данные об изменении сенсомоторных показателей у геймеров (студентов 19-20 лет, играющих в компьютерные игры не менее 6 часов в день на протяжении последних 6 лет). Было зафиксировано увеличение времени реакции геймеров на зрительные, тактильные и слуховые сигналы как в состоянии относительного покоя, так и в условиях умственной нагрузки. Это может свидетельствовать о снижении скорости переработки информации активными киберигроками уже на этапе ее восприятия.

Наряду с абсолютными показателями скорости реагирования на сигналы, отражающими уровень активности нервной системы, анализировалась величина изменения времени 
реакции, т. е. активация сенсорных зон в условиях умственной нагрузки. В частности, были зафиксированы меньшие по сравнению с другими группами (пользователей и разработчиков) функциональные возможности левополушарных сенсорных зон при увеличении умственной нагрузки. Кроме того, характер активации сенсорных зон геймеров был менее адекватен предлагаемому экспериментальному материалу, нежели у представителей контрольных групп. Было установлено, что у активных киберигроков наблюдается выраженное торможение на второе предъявление сигнала одной и той же модальности. Это свидетельствует об изменении структурной организации функциональных систем, реализующих познавательные способности геймеров. Данные результаты дают основание предполагать, что у активных киберигроков со стажем изменяется микрогенез функциональных систем, иначе говоря, природа познавательного процесса, в частности мнемического.

Микрогенез функциональной системы, которая реализует конкретное психическое свойство, есть процесс выстраивания взаимосодействия различных психофизиологических механизмов для достижения конкретного результата. В связи с этим очевидно, что способности, обусловленные генезисом функциональной системы, зрелостью мозговых структур, в частности, сенсорных зон, а также механизмов «перепрограммирования» (по мнению А.Р. Лурии) корковой активности, будут изменяться. При этом для «запуска» процесса формирования конкретной функциональной системы необходимо определенное внешнее воздействие. Вновь возникающий внешний раздражитель стимулирует возникновение новых связей, т. е. новой функциональной системы, структурная организация которой может закрепляться путем генерализации условий деятельности и ее стереотипизации, как писал в свое время С.Л. Рубинштейн.

В связи с этим есть основание предполагать, что различные виды Интернет-деятельности создают условия для формирования специфических и, вероятно, ограниченных по своим потенциальным возможностям функциональных систем.

Развитые способности реализуются разноуровневыми механизмами: функциональными, операционными и регулирующими (Черемошкина, 2000, 2009а, б). Функциональные механизмы как генотипическая и врожденно обусловленная основа способностей поддаются тренировке с учетом степени задействованности той или иной анализаторной системы. Познавательная, коммуникативная и игровая деятельность с помощью Интернет-ресурсов реализуется с преимущественным использованием зрительного восприятия. Поэтому с большой долей уверенности можно предполагать рост продуктивности зрительных перцептивных и мнемических способностей по отношению к наглядно представленному материалу, обусловленному развитием их функциональных механизмов.

Операционные механизмы познавательных способностей представляют собой способы обработки (анализа, осмысления) информации. Они полифункциональны и формируются 
по мере созревания мозговых структур и развития интеллекта субъекта деятельности. Характер и условия деятельности, вид обрабатываемой информации накладывают отпечаток на качественное своеобразие (сложность, разнообразие, гибкость в применении и т. д.) операционной стороны когнитивной сферы человека (Черемошкина, 2009в).

Развитие операционных механизмов конкретной познавательной способности обусловлено формированием наиболее сложных умственных действий, направленных на организацию целостного познавательного акта от ориентировки до антиципации возможного результата.

Активное использование Интернет-ресурсов может, с одной стороны, приводить к появлению новых способов обработки информации и, следовательно, к изменению структуры познавательных способностей. С другой стороны, виртуальный характер пространства-времени и социального взаимодействия создает принципиально другие условия для формирования и развития не только операционных, но и регулирующих механизмов познавательных способностей.

Наши исследования данной проблемы, начатые в 2004 г., указывают на следующие тенденции.

1.Снижается возраст вовлеченности в Интернет-активность. По дан- ным 2010 г.,$\quad$ 7\% 11-классников начали использовать Интернет-ресурсы с 7 лет, 37\% - с 12 лет. При этом среди шестиклассников уже $29 \%$ знакомы с интернетом с 7 лет, а 3\% - с 3.5 лет.

2. Растет количество пользователей кибер- и Интернет-ресурсами в профессиональной, познавательной, коммуникативной и игровой сферах.

3. Растет количество киберигроков и снижается возраст обращения к киберигровой активности. Среди 11-классников 64\% играют в компьютерные игры ежедневно, а среди шестиклассников играет абсолютное большинство, в среднем до полутора часов каждый день (по материалам опроса детей).

\section{Испытуемые и метод исследования}

Целью настоящей работы явилось продолжение исследований влияния Интернет-активности на мнемические способности пользователя. Пользователь Интернет-ресурсов, по нашим данным, обращается к Сети как в профессиональных и познавательных, так и в коммуникативных и игровых целях. При этом Интернет-ресурсы выступают для пользователя в качестве условий (или одного из условий), в которых разворачивается его повседневная и профессиональная активность; по

\footnotetext{
${ }^{1}$ Опрос учащихся 6-х (36 человек) и 11-х (28 человек) классов московских школ показал:

7\% 11-классников начали пользоваться Интернет-ресурсами с 7 лет, 14\% - с 9 лет, 14\% с 10 лет, $28 \%$ - с 11 лет, $37 \%$ - с 12 лет.

Среди шестиклассников 3\% начали использовать Интернет-ресурсы с 3.5 лет, 3\% - с 4 лет, $3 \%$ - с 5 лет, $30 \%$ - с 6 лет, $29 \%$ - с 7 лет, $5 \%$ - с 8 лет, $8.5 \%$ - с 9 лет, $13.5 \%$ - с 10 лет, $5 \%$ с 12 лет.
} 
сравнению с теми, для кого создание информационных технологий является сознательно выбранной целью или мотивом, имеющим воплощение исключительно в киберпространстве. Стаж и продолжительность ежедневного пребывания в Сети рассматривались нами как показатель активности.

Выявленные ранее закономерности развития и функционирования памяти школьников 11 лет, подростков, студентов и взрослых (Черемошкина, 2000, 2009а), а также результаты упоминавшегося выше опроса обусловили целесообразность изучения мнемических способностей Интернет-активных пользователей данных возрастных групп и необходимость формирования следующих экспериментальных выборок. Первая выборка состояла из 33 учащихся общеобразовательных школ г. Железнодорожный Московской области в возрасте 11 лет (данные А.Е. Харитонова).

Вторая выборка состояла из 82 учащихся общеобразовательных школ Орехово-Зуевского района Московской области в возрасте 16 лет.

Третья выборка состояла из 62 студентов московских вузов в возрасте 18-20 лет.

Четвертая выборка состояла из 26 пользователей 25-35 лет (все с высшим образованием: менеджеры, системные администраторы, преподаватели).

По результатам опроса в каждой из выборок были сформированы экспериментальные группы:

- со стажем Интернет-активности до года и до полутора лет; от года до трех; от полутора до трех лет; свыше трех лет среди школьников;
- со стажем свыше трех лет и свыше шести лет среди студентов;

- со стажем свыше 10 лет среди взрослых пользователей.

Длительность пребывания в Сети активных пользователей составляет не менее 4 часов в день и не реже 5 дней в неделю.

Контрольные группы в первой и второй выборках составили непользователи Интернет-ресурсов и неактивные пользователи (длительность пребывания в Сети не более 1.5 часов в неделю) со стажем знакомства с Интернетом не более полугода.

Для оценки проявления мнемических способностей применялся метод развертывания мнемической деятельности В.Д. Шадрикова, Л.В. Черемошкиной (Шадриков, Черемошкина, 1990; Черемошкина, 2009б). Данный метод направлен на изучение эффективности памяти, уровня ее развития, а также качественного своеобразия мнемических приемов и способов их регуляции. Метод развертывания мнемической деятельности осуществляется с использованием 10 карточек с изображенными на них фигурами нарастающей сложности, которые состоят из прямых пересекающихся линий.

Время предъявления каждой карточки следующее: с 1-го по 10-е предъявление - 1 с; с 11-го по 20-е 2 c; с 21-го по 30-е - 3 с; и т. д. Невербальный бессмысленный материал и указанный выше порядок его предъявления позволяют «развернуть» мнемическую деятельность и вычленить продуктивность реализующих ее механизмов: функциональных, операционных и регулирующих.

В данном исследовании с помощью метода развертывания 
мнемической деятельности оценивались 3 показателя:

1) продуктивность запоминания с опорой на функциональные механизмы; для этого использовалась карточка № 2;

2) эффективность запоминания благодаря функциональным и операционным механизмам, для этого использовалась карточка № 3;

3) эффективность запоминания благодаря функциональным, операционным и регулирующим механизмам, для этого использовалась карточка № 10.

В качестве показателей рассматривалось время запоминания карточек № 2, № 3, № 10 (см. рисунок 1). Подробное описание метода приведено в других работах (Шадриков, Черемошкина, 1990; Черемошкина, 2009б).

Для получения дополнительной информации применялся опрос по 30 вопросам, рекомендованным в методике диагностики мнемических способностей (Шадриков, Черемошкина, 1990; Черемошкина, 2009б). Опрос испытуемого после запоминания различного по сложности материала позволяет сделать выводы:

- о наличии или отсутствии мнемических приемов;
- о их количестве и разнообразии;

- о скорости включения мнемических приемов в процесс запоминания;

- об уровне развития регулирующих механизмов мнемических способностей.

Итак, изучались показатели эффективности мнемических способностей школьников 11 и 16 лет с различным стажем использования Интернет-ресурсов, а также аналогичные показатели Интернет-активных студентов 18-20 лет со стажем более трех и свыше шести лет, а также взрослых пользователей 25-35 лет со стажем свыше десяти лет.

\section{Результаты и их обсуждение}

Показатели скорости запоминания простого и усложненного материала выделенных групп Интернет-активных школьников 11 лет и контрольной различаются (таблица 1), но без статистической подтвержденности их значимости. По этим же показателям между группами интернет-активных школьников 16 лет и контрольной обнаружены различия (таблица 2), но также без статистической подтвержденности их значимости.

\section{Карточки № 2, № 3 и № 10}
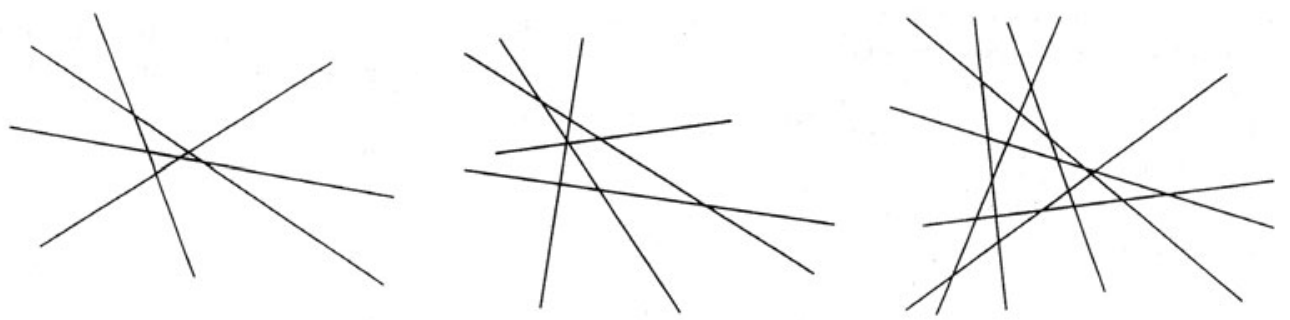
Исследование мнемических способностей выявило значимые различия между Интернет-активными студентами со стажем свыше трех и шести лет и взрослыми пользователями 25-35 лет со стажем свыше десяти лет по показателям скорости запоминания простого, усложненного и наиболее сложного материала ( $p<0.05$ по критерию Стьюдента) (таблицы 3 и 4).

Выявленная тенденция в изменении показателей запоминания с опорой на функциональные механизмы свидетельствует: чем больше стаж Интернет-активности, тем выше скорость запоминания простого материала, иначе говоря, выше продуктивность запоминания с опорой на функциональные механизмы. Среднее время запоминания простого материала Интернет-активными школьниками 11 лет со стажем свыше трех лет составляет 8.75 с против 15 с, являющихся средним показателем запоминания группой со стажем от года до трех лет. Аналогичный показатель контрольной группы оказался меньше, нежели у группы со стажем интернет-активности до года, но на 5 с больше, чем у Интернет-активных школьников 11 лет со стажем свыше трех лет.

Эффективность запоминания с опорой на функциональные и операционные механизмы 11-летних со стажем Интернет-активности свыше трех лет составила 27.2 с, что среди

Таблииа 1

Средние показатели эффективности мнемических способностей школьников 11 лет

\begin{tabular}{|l|c|c|}
\hline \multirow{2}{*}{$\begin{array}{c}\text { Группы испытуемых с } \\
\text { различным стажем } \\
\text { Интернет-активности }\end{array}$} & \begin{tabular}{|}
$|c|$ \\
Показатели эффективности
\end{tabular} \\
\cline { 2 - 3 } & $\begin{array}{c}\text { Время запоминания } \\
\text { простого материала (c) }\end{array}$ & $\begin{array}{c}\text { Время запоминания } \\
\text { усложненного материала (c) }\end{array}$ \\
\hline До года & 19 & 52.2 \\
\hline От года до трех лет & 15 & 38.2 \\
\hline Свыше трех лет & 8.75 & 27.2 \\
\hline Контрольная группа & 14 & 28 \\
\hline
\end{tabular}

Таблииа 2

Средние показатели эффективности мнемических способностей школьников 16 лет

\begin{tabular}{|l|c|c|}
\hline \multirow{2}{*}{$\begin{array}{c}\text { Группы с различным стажем } \\
\text { интернет-активности }\end{array}$} & \multicolumn{2}{|c|}{ Показатели эффективности } \\
\cline { 2 - 3 } & $\begin{array}{c}\text { Время запоминания } \\
\text { простого материала (c) }\end{array}$ & $\begin{array}{c}\text { Время запоминания } \\
\text { усложненного материала (c) }\end{array}$ \\
\hline До полутора лет & 13.2 & 28 \\
\hline От полутора до 3 лет & 9.5 & 33 \\
\hline Свыше 3 лет & 7 & 25 \\
\hline Контрольная группа & 17.5 & 30 \\
\hline
\end{tabular}


выделенных групп является минимальным результатом. Стоит отметить, что аналогичный показатель контрольной группы, составляющий 28 с, меньше скорости запоминания обеих групп со стажем Интернет-активности до года и от года до трех лет (52.2 с и 38.2 с соответственно).

Таким образом, получены результаты, свидетельствующие о том, что скорость запоминания школьниками 11 лет, имеющими стаж использования Интернет-ресурсов более трех лет, как простого, так и усложненного материала выше, чем у представителей других экспериментальных групп (на уровне проявляющейся тенденции без статистической подтвержденности значимости полученных различий).

Шестнадцатилетние школьники со стажем Интернет-активности свыше трех лет продемонстрировали лучшие по сравнению со сверстниками показатели запоминания как простого, так и усложненного материала (7 с и 25 с соответственно) (см. таблицу 2).

Время запоминания простого материала всех экспериментальных групп ниже, нежели аналогичные показатели контрольной (13.2 c; 9.5 c; 7 с соответственно против 17.5 с в контрольной группе). При этом зафиксировано увеличение скорости запоминания невербального бессмысленного материала в связи с увеличением стажа использования Интернет-ресурсов.

Разница в средних показателях запоминания усложненного материала между экспериментальной и контрольной группами незначительна. Эффективность запоминания благодаря функциональным и опе- рационным механизмам в группе со стажем Интернет-активности до полутора лет составила 28 с по сравнению с аналогичным показателем в контрольной группе $(30.5$ с). При этом наиболее низкая успешность запоминания усложненного материала зафиксирована в группе со стажем Интернет-активности от полутора до трех лет и составила в среднем 33 с. Наиболее высокая скорость запоминания данного материала оказалась в группе со стажем Интернет-активности свыше трех лет - 25 с. Полученные результаты подтверждают проявившуюся на выборке одиннадцатилетних тенденцию: чем больше стаж Интернет-активности, тем выше продуктивность запоминания с опорой на функциональные механизмы, а также благодаря функциональным и операционным механизмам мнемических способностей.

Продуктивность запоминания с опорой на функциональные механизмы у студентов выше в 2 раза, нежели у взрослых пользователей со стажем свыше 10 лет (4 с и 3.3 с по сравнению с 8 с у последних). Скорость запоминания простого материала у студентов со стажем Интернет-активности свыше трех лет и свыше шести лет является наиболее высокой и по сравнению с аналогичными показателями школьников 11 и 16 лет (4 с, 3.3 с у студентов и 8.75 с у школьников 11 лет со стажем свыше трех лет; 7 с у школьников 16 лет со стажем свыше трех лет). Следует отметить, что разница в продуктивности запоминания с опорой на функциональные механизмы между группами студентов с различным стажем Интернет-активности минимальна. 
Время запоминания усложненного материала у студентов со стажем свыше трех лет составляет 5.6 с и является минимальным по сравнению с аналогичными показателями исследуемых нами групп испытуемых. При этом скорость запоминания данного материала студентами со стажем свыше шести лет составила 13.8 с, что превышает более чем в 2 раза данный показатель у студентов со стажем свыше трех лет (см. таблицу 3).

Особо следует подчеркнуть, что часть испытуемых не смогла запомнить наиболее сложное задание, причем более успешными оказались студенты со стажем свыше трех лет.
Показатели эффективности мнемических способностей пользователей со стажем свыше 10 лет (см. таблицу 4) значимо $(p<0.05)$ отличаются от аналогичных показателей студентов и составляют 8 с и 28 с при запоминании простого и усложненного материала. Эти результаты сопоставимы с показателями запоминания данного материала школьниками 11 и 16 лет, имеющими стаж Интернет-активности свыше трех лет.

Скорость запоминания наиболее сложного материала пользователями со стажем свыше 10 лет составляет более 2 мин. Следует отметить, что более половины выборки

Таблица 3

Средние показатели эффективности мнемических способностей студентов

\begin{tabular}{|c|c|c|c|c|}
\hline \multirow{2}{*}{$\begin{array}{c}\text { Группы с } \\
\text { различным } \\
\text { стажем } \\
\text { Интернет- } \\
\text { активности }\end{array}$} & $\begin{array}{c}\text { Время } \\
\text { запоминания } \\
\text { простого } \\
\text { материала (c) }\end{array}$ & $\begin{array}{c}\text { Время } \\
\text { запоминания } \\
\text { усложненного } \\
\text { материала (c) }\end{array}$ & $\begin{array}{c}\text { Время } \\
\text { запоминания } \\
\text { сложного } \\
\text { материала (c) }\end{array}$ & $\begin{array}{c}\text { Процент } \\
\text { спавившихся с } \\
\text { наиболее } \\
\text { сложным } \\
\text { заданием }\end{array}$ \\
\hline Свыше 3 лет & 4 & 5.6 & 45 & 90 \\
\hline Свыше 6 лет & 3,3 & 13.8 & 68 & 72 \\
\hline
\end{tabular}

Таблица 4

Средние показатели эффективности мнемических способностей пользователей 25-35 лет

\begin{tabular}{|c|c|c|c|c|}
\hline \multirow{2}{*}{$\begin{array}{c}\text { Группы с различным } \\
\text { стажем Интернет- } \\
\begin{array}{c}\text { активности } \\
$\cline { 2 - 5 }\end{array}\end{array}} & $\begin{array}{c}\text { Время } \\
\text { запоминания } \\
\text { простого } \\
\text { материала (c) }\end{array}$ & $\begin{array}{c}\text { Время } \\
\text { запоминания } \\
\text { усложненного } \\
\text { материала (c) }\end{array}$ & $\begin{array}{c}\text { Время } \\
\text { запоминания } \\
\text { сложного } \\
\text { материала (c) }\end{array}$ & $\begin{array}{c}\text { Процент } \\
\text { спавившихся с } \\
\text { наиболее } \\
\text { сложным } \\
\text { заданием }\end{array}$ \\
\hline $\begin{array}{l}\text { Пользователи со } \\
\text { стажем Интернет-ак- } \\
\text { тивности свыше } 10 \text { лет }\end{array}$ & 8 & 28 & 135 & 45 \\
\hline
\end{tabular}


(55\%) не справились с этим заданием.

Различия по эффективности мнемических способностей между Интернет-активными студентами и взрослыми пользователями со стажем свыше 10 лет увеличиваются на этапе запоминания наиболее сложного материала (135 с по сравнению с 45 с и 68 с у студентов со стажем свыше 3 и 6 лет).

Таким образом, полученные результаты свидетельствуют о снижении эффективности мнемических способностей пользователей со стажем свыше 10 лет по сравнению с аналогичными показателями студентов. Кроме того, полученные данные демонстрируют отчетливо проявляющуюся тенденцию увеличения продуктивности запоминания с опорой на функциональные механизмы школьников 11 и 16 лет со стажем свыше трех лет.

Скорость запоминания невербального бессмысленного материала пользователями Интернет-ресурсов со стажем свыше 3, 6 и 10 лет позволяет констатировать, что длительность и систематичность применения Интернет-ресурсов в познавательных, коммуникативных, игровых целях оказывает влияние на мнемические способности.

Результаты запоминания простого и усложненного материала школьниками 11 лет с различным стажем использования Интернет-ресурсов показывает рост продуктивности запоминания с опорой на функциональные механизмы у школьников со стажем свыше 3 лет. Это позволяет предполагать, что сочетание познавательной, коммуникативной и игровой деятельности в Сети оказывает развивающее воздействие на функциональную основу памяти. Кроме того, результаты запоминания основного материала растут вследствие развитости операционных механизмов и скорости их включения в процесс запоминания. Необходимо отметить, что данный возраст при условии наличия учебной деятельности в качестве ведущей характеризуется активным развитием операционной стороны памяти и появлением регулирующих механизмов (Черемошкина, 2009в). Эти процессы качественных преобразований памяти должны в наибольшей степени проявляться при запоминании усложненного материала, того, который нельзя запечатлеть с помощью функциональных механизмов.

Результаты опроса 11-летних испытуемых позволяют зафиксировать качественные изменения операционной стороны мнемических способностей по мере увеличения стажа использования Интернет-ресурсов. В частности, появляется способность запоминать по аналогии с чем-либо хорошо известным: 9\% со стажем до года и 9\% от полутора до 3 лет, а также почти 17\% свыше трех лет отметили попытки найти сходство запоминаемой фигуры с чем-либо. Представители контрольной группы отвечали на этот вопрос отрицательно.

Другим показательным моментом является заметный рост осознанности применения группировки: $82 \%$ со стажем до года, 63\% - от полутора до трех и 68\% со стажем свыше трех лет против $60 \%$ в контрольной группе могли ответить на вопрос о том, какие части, элементы фигуры было сложнее запоминать. Эти ответы полностью подтверждаются 
результатами опроса об использовании повторения. Ответы на вопрос: старался ли ты каким-либо образом повторить то, что запоминаешь, $80 \%$ представителей контрольной группы ответили утвердительно. При этом среди вовлеченных в Интернет-активность только $45 \%$ со стажем до года, $73 \%$ со стажем от полутора до трех лет и $33 \%$ свыше трех лет отметили наличие целенаправленного повторения фигур, которые таким образом запомнить сложно. Это свидетельствует о развитой и развивающейся ориентировке в материале, которая направлена скорее на понимание, анализ и осознание материала, нежели на его механическое заучивание. Интернет-активные 11-летки не стремились повторять материал, они пытались достроить фигуру до понятной, знакомой, приемлемой: $73 \%$ со стажем до года, $64 \%$ со стажем от полутора до трех лет и $67 \%$ со стажем свыше трех лет по сравнению с $60 \%$ в контрольной группе. Следует при этом подчеркнуть, что Интернет-активные школьники 11 лет на вопросы: старался ли ты понять расположение линий, пытался ли ты выделить в запоминаемой фигуре треугольники, лучи, кресты, реже, чем в контрольной, отвечали утвердительно: $91 \%$ со стажем до года, $82 \%$ - от полутора до трех лет и $84 \%$ - со стажем свыше трех лет. Это может свидетельствовать об иных вариантах структурирования материала Интернет-активными субъектами. Результат запоминания фигуры № 3 за 52 с может свидетельствовать о развивающейся аналитичности. Данная тенденция была зафиксирована нами ранее при изучении особенностей когнитивной сферы «жителей» Интер- нета и программистов (Черемошкина, 2006, 2009б). Тенденция в сторону аналитичности перцептивной деятельности, по нашим данным, значимо «удлиняет» процесс запоминания.

Результаты запоминания простого и усложненного материала школьниками 16 лет, а также материалы опроса (опрос проводился А.В. Кузнецовой) подтверждают проявляющуюся на выборке 11-летних тенденцию. Систематическое и длительное использование Интернет-ресурсов оказывает влияние не только на функциональную основу памяти, но и на операционные и регулирующие механизмы. В частности, растет скорость включения операционных механизмов в процесс запоминания. Это свидетельствует о развитии взаимодействия функциональных и операционных механизмов.

В группе 16-летних со стажем до полутора и от полутора до трех лет более $40 \%$ испытуемых отметили применение способов обработки материала в процессе запоминания карточки № 2, а 15\% - уже на стадии пробного задания. При этом $36 \%$ 16-летних со стажем свыше трех лет и только 15\% представителей контрольной группы отметили, что момент включения операционных механизмов в процесс запоминания приходится на первые предъявления пробного задания.

Качественный состав мнемических приемов школьников 16 лет со стажем свыше трех лет отличается рядом особенностей. Во-первых, они не применяют перекодирования. Иначе говоря, запоминание бессмысленного невербального материала не сопровождается обозначением или 
называнием. При этом 27\% со стажем от полутора до трех лет, 36\% со стажем до полутора лет и 23\% представителей контрольной группы старались ускорить процесс запоминания с помощью перекодирования. Возможно, среди наших испытуемых гораздо больше геймеров, нежели показали результаты опроса, а киберигровая деятельность может, как известно, совершаться без участия речи. Во-вторых, 16-летние со стажем свыше трех лет не стремились запоминать однотипно усложняющийся материал по аналогии. Это может показывать их нежелание или неспособность упрощать воспринимаемый материал. Возможно, чем больше стаж использования Интернет-ресурсов, тем выше вероятность того, что субъект каждую вновь поступающую информацию изучает безотносительно к предыдущей. При этом, несмотря на указанные особенности, в группе 16-летних со стажем свыше трех лет отсутствуют низкие показатели запоминания усложненного материала. Это показывает развивающее влияние интернет-ресурсов на системное взаимодействие функциональных, операционных и регулирующих механизмов.

Показатели запоминания Интернет-активных студентов и взрослых пользователей (см. таблицы 3 и 4), а также материалы опроса позволяют зафиксировать влияние Интернет-активности на разноуровневые механизмы мнемических способностей. Очень высокая скорость запоминания простого материала студентами свидетельствует о высокой продуктивности функциональной основы их памяти. Можно предположить, что активное использование
Интернет-ресурсов в различных целях создает условия для поддержания некоего «тонуса» функциональных механизмов, что находит конкретное результативное выражение на уровне оперативной или рабочей памяти. В данной ситуации следует говорить именно об оперативной или рабочей памяти, так как операционные механизмы включались в процесс запоминания на первом предъявлении пробной карточки.

Материалы опроса как студентов, так и взрослых пользователей отличаются развернутостью. Это свидетельствует не только о присутствии сознательной обработки материала, но и о развитых регулирующих механизмах. Как взрослые пользователи, так и студенты формировали план запоминания и усложненного и наиболее сложного материала, искали способы контроля процесса запоминания. Абсолютное большинство использовали структурирование, оперируя при запоминании и 3-й и 10-й фигур не линиями и палочками, а треугольниками. Причем характер ответов успешных и тех, кто не справился с заданием, почти не различался: сначала выделялся опорный пункт, который являлся структурной единицей фигуры, в дальнейшем особое внимание уделялось пересечениям. Иначе говоря, и студенты, и взрослые пользователи по всем показателям характеризуются развитыми мнемическими способностями, предполагающими высокие результаты при запоминании материала любой сложности. Но в данном случае почти треть студентов со стажем свыше 6 лет и более половины взрослых пользователей не справились с запоминанием наиболее 
сложного материала. Возможно, они старались включить весь свой операциональный резерв уже на стадии запоминания усложненного материала. Это может приводить к быстрому истощению, к желанию переключиться на другую деятельность. Однако процедура эксперимента сделать этого не позволяла. В результате регулирующие механизмы как бы «расщепляются»: внутренняя регуляция (действия планирования, контроля, коррекции и др.) отчетливо представлена (проговаривается), но не «сопрягается» с целью, мотивом или смыслом деятельности. Аналогичные результаты были получены нами при изучении когнитивной сферы разработчиков компьютерных программ со стажем и активных киберигроков со стажем (Черемошкина, Никишина, 2008; Черемошкина и др., 2009), у которых зафиксирована подобная деформация регулирующих механизмов. Остановимся на этом моменте подробнее. Регулирующие механизмы представляют собой системное взаимодействие контролирующих, корректирующих, антиципирующих и др. операций, действие которых обусловлено мотивами, волевыми и эмоциональными процессами. Данное взаимодействие конкретизируется в цели деятельности. Ни указанные операции, ни целеполагающая активность не совершаются помимо сознания. Следовательно, если те или иные виды или формы активности приводят к деформации регулирующих механизмов, это означает наличие их негативного влияния на сознание человека. В данном случае в качестве такого фактора выступает стаж Интернет-деятельности. Исполь- зование Интернет-ресурсов для получения информации способно воздействовать на сознание пользователя, оказывая влияние на его память как систему организации информации в целях предстоящей деятельности. В случае активного использования Интернет-ресурсов субъекту нет необходимости запоминать значительные массивы информации, так как она находится в постоянном доступе. Кроме того, в условиях виртуальной реальности человек чаще проявляется как потребитель, нежели как созидатель, а это снижает интенсивность целеполагающей и целеобразовательной деятельности.

Социальное взаимодействие в виртуальном пространстве привлекает анонимностью и возможностями самореализации через использование новых ролей. Анонимность плюс частая смена ролей рождает стереотипные поведенческие реакции со сниженным сознательным контролем и создает условия для разрегулированния психической деятельности. Игровая активность в кибер-, Интернет-среде является мощным фактором вовлечения в виртуальный мир, где субъект постепенно перестает быть субъектом, его активность определяется не его сознанием, а игрой, не его логикой, а логикой создателя игры. Со временем активному киберигроку становится все сложнее и энергозатратнее возвращаться в реальный мир, в котором необходимо самостоятельно выстраивать поведение, а чаще исправлять результаты своих непродуманных и спонтанных шагов. Учитывая то, что геймеры со стажем даже в условиях простой умственной нагрузки включают все свои резервы (в частности, 
при запоминании простого образного материала задействуют левополушарные структуры), то легко представить ситуацию, когда они отказываются от деятельности в условиях сложной задачи, не выдерживая нервно-психического напряжения. По всей вероятности, игра порождает у геймера сильную доминанту (по А.А. Ухтомскому), а выход из игры, следовательно, сопровождается торможением, приводящим к слабо контролируемому поведению. Таким образом, использование Интернет-ресурсов, помимо очевидных плюсов, способно оказывать и негативное воздействие на психические процессы, в частности, на процессы регуляции когнитивной активности.

\section{Выводы}

Длительное и систематическое использование Интернет-ресурсов в познавательных, игровых и коммуникативных целях оказывает влияние на мнемические способности субъекта.

Выявленные нами различия в эффективности запоминания простого, усложненного и наиболее сложного невербального бессмысленного материала между студентами со стажем Интернет-активности свыше трех и свыше шести лет и пользователями 25-35 лет со стажем свыше 10 лет согласуются с ранее полученными фактами о подверженности влиянию информационных технологий как функциональных и операционных, так и регулирующих механизмов мнемических способностей активного пользователя (Черемошкина, 2006, 2008, 2009а, 2009б; Черемошкина, Никишина, 2008; Черемошкина и др., 2009).

\section{Литература}

Пиаже Ж. Характер объяснений в психологии и психофизиологический параллелизм // Экспериментальная психология. М., 1966. Вып. 1-2.

Черемошкина Л.В. Влияние интернет-активности на познавательные способности субъекта // Материалы 2-й Всероссийской научной конференции «Психология индивидуальности». М.: Изд. дом ГУ-ВШЭ, 2008. С. 169-170.

Черемошкина Л.В. Влияние интернетактивности на развитие познавательных и личностных процессов // Материалы 4-й Международной конференции «Европа и современная Россия: функция

педагогической науки в едином образовательном пространстве». М., 2006. C. 16-19.

Черемошкина Л.В. Влияние интернет-деятельности на коммуникативные и когнитивные процессы субъекта // Познание в структуре общения / Под ред. В.А. Барабанщикова, Е.С. Самойленко. М.: Изд-во ИП РАН, 2009а. С. 331-340.

Черемошкина Л.В. Психология мнемических способностей: Дис.... докт. психол. наук. 2000.

Черемошкина Л.В. Влияние информационных технологий на развитие личности: особенности картины мира и когни- 
тивной сферы носителей интернет-культуры // Ярославский психологический вестник. М.-Ярославль: Изд-во «Российское психологическое общество», 2009б. Вып. 25. С. 148-156.

Черемошкина Л.В. Психология памяти. М.: Аспект Пресс, 2009в.

Черемошкина Л.В., Никишина Н.А. Нейропсихологические аспекты эффективности мнемических способностей ак- тивных киберигроков // Вестник РГНФ. 2008. № 3. C. 176-183.

Черемошкина Л.В., Никишина Н.А., Харитонов А.E. Эффективность мнемических способностей и время реакции геймеров // Вопросы психологии. 2009. № 5. С. $84-93$

Шадриков В.Д., Черемошкина Л.В. Мнемические способности: Развитие и диагностика. М.: Педагогика, 1990. 